\title{
ANTIBACTERIAL EFFICACY OF 6\% GREEN TEA EXTRACT AND 2\% CHLORHEXIDINE AGAINST ENTEROCOCCUS FAECALIS BIOFILM IN VITRO
}

\section{FITRI REFLAN, RATNA MEIDYAWATI*, DARU INDRAWATI}

Department of Conservative Dentistry, Faculty of Dentistry, Universitas Indonesia, Jakarta, 10430, Indonesia. E-mail: meidyawati58@gmail.com Received: 27 August 2018, Revised and Accepted: 07 February 2019

\begin{abstract}
Objective: This study aimed to compare the antibacterial efficacy of green tea extract to chlorhexidine $2 \%$ against Enterococcus faecalis biofilm using real-time polymerase chain reaction (RT-PCR).

Methods: E. faecalis strain ATCC 29212 colonies were collected from overnight cultures grown on brain-heart infusion agar (BHIA) and resuspended at $10^{8} \mathrm{CFU} / \mathrm{ml}$ according to a $0.5 \mathrm{McFarland}$ standard. Aliquots of bacterial suspension ( $50 \mu \mathrm{l}$ ) were then inoculated onto sterile nitrocellulose filter discs place on BHIA and incubated aerobically at $37^{\circ} \mathrm{C}$ for $72 \mathrm{~h}$. After incubation, the discs were removed, transferred into 10 -ml phosphate-buffered saline (PBS) to loosen planktonic bacteria, and then incubated for $10 \mathrm{~min}$ at $37^{\circ} \mathrm{C}$ in $10 \mathrm{ml}$ of $6 \%$ green tea extract, $2 \%$ chlorhexidine, or sterile PBS (control). Surviving E. faecalis cells were then quantified by RT-PCR.
\end{abstract}

Results: Green tea extract reduced bacterial survival compared to control but was not as effective as chlorhexidine $2 \%$.

Conclusion: Green tea extract may help reduce oral E. faecalis biofilm. Moreover, specific antimicrobial compounds in green tea extract such as epigallocatechin-3-gallate should be tested as non-toxic alternatives to chlorhexidine.

Keywords: Enterococcus faecalis, Green tea extract, chlorhexidine 2\%, Real-time polymerase chain reaction.

(C) 2019 The Authors. Published by Innovare Academic Sciences Pvt Ltd. This is an open access article under the CC BY license (http://creativecommons. org/licenses/by/4. 0/) DOI: http://dx.doi.org/10.22159/ijap.2019.v11s1.168

\section{INTRODUCTION}

The success of root canal treatment is dependent on the effective elimination of microbes and irritants from the root canal system, which prevents reinfection and promotes healing. Bacteria remain in the root canal following mechanical cleaning due to the complexity of root canal anatomy, so an irrigation solution is also needed to clean and help remove residual bacteria. However, some bacterial species can survive even in prepared, irrigated, and obturated root canals, such as Enterococcus faecalis, which contributes to the persistence of periradicular lesions after root canal treatment. E. faecalis is resistant to several tested antibacterial agents, can invade and live in dentinal tubules, and can form biofilms that make it 1000 times more resistant to phagocytic agents, antibodies, and antimicrobials [1].

Many studies have examined the most effective way for removing E. faecalis from the root canal, and chlorhexidine has shown particularly high efficacy [2-5]. However, chlorhexidine is a synthetic chemical with known toxicity against certain cells, such as fibroblasts, polymorphonuclear leukocytes (PMNs), and other leukocytes, macrophages, and erythrocytes. Therefore, it would be advantageous to identify natural agents with strong antibacterial efficacy against E. faecalis but low toxicity against mammalian cells to enhance the biosafety of bacterial clearance during root canal treatment. For instance, green tea is known to have antioxidant, antimutagenic, anticarcinogenic, and antimicrobial effects $[2,4]$. While several studies have been conducted to test the antibacterial efficacy of green tea extract, none have directly compared its antibacterial effect to $2 \%$ chlorhexidine solution against E. faecalis bacteria in biofilm.

\section{METHODS}

Culture of Enterococcus faecalis ATCC 29212

E. faecalis strain ATCC 29212 was smeared evenly onto brain-heart infusion agar (BHIA) and incubated for $24 \mathrm{~h}$ at $37^{\circ} \mathrm{C}$, by which time bacterial colonies were clearly visible. E. faecalis colonies were drawn into needles and transferred to test tubes containing $10-\mathrm{ml}$ sterile saline, and the density was adjusted to $10^{8} \mathrm{CFU} / \mathrm{ml}$ using a 0.5 McFarland standard solution.

\section{Preparation of Enterococcus faecalis biofilm}

A sterile cellulose nitrate filter membrane (pore size $0.2,13 \mathrm{~mm}$ in diameter) was placed on top of BHIA, and $25 \mu \mathrm{l}$ of the standardized E. faecalis suspension was added using a micropipette. Membranes containing the bacterial suspension were incubated at $37^{\circ} \mathrm{C}$ for $72 \mathrm{~h}$ under aerobic conditions and then treated with phosphate-buffered saline (PBS) (control), chlorhexidine $2 \%$, or $6 \%$ green tea extract as described below.

\section{Preparation of green tea extract}

Green tea extract was prepared from imperial green tea leaves obtained from the Tea and Kina Gambung Research Center (Bandung, West Java, Indonesia). Imperial tea is produced from tea leaf buds that have not yet bloomed and processed using a steaming system. Briefly, dried imperial green tea leaves were crushed and sieved to form a fine powder. A $250-\mathrm{g}$ sample of tea powder was then fed into an extractor gourd with $2.5 \mathrm{l}$ of distilled water. The mixture was placed over a heater to evaporate for $1 \mathrm{~h}$ at a temperature below $80^{\circ} \mathrm{C}$. The insoluble particles were removed by a Mesh 250 filter, and the filtrate was transferred to Erlenmeyer flasks. Initial filtrate volume (V1) was about $2200 \mathrm{ml}$. The extract content was tested (\%E for V1) and then evaporated using a vacuum rotary evaporator at an operating temperature below $80^{\circ} \mathrm{C}$ until the final volume (V2) was about $180 \mathrm{ml}$ and $\% \mathrm{E}$ reached $45.50 \%$. The green tea extract was diluted to $6 \%$ in sterile Aqua Bidest double-distilled water using the formula C1.V1=C2.V2 and filtered through $0.2-\mu \mathrm{m}$ membranes.

Treatment of Enterococcus faecalis ATCC 29212 biofilms

After incubation for $72 \mathrm{~h}$, E. faecalis cultures growing in cellulose nitrate membranes on BHIA were transferred into Eppendorf tubes with $1 \mathrm{ml}$ of 
Table 1: Mean Enterococcus faecalis survival after treatment

\begin{tabular}{llll}
\hline 95\% IK treatment & n & Mean \pm SD & Lower limit \\
\hline Green tea 6\% & 3 & $4.64 \times 10^{7} \pm 012 \times 10^{7}$ & $4.35 \times 10^{7}$ \\
Chlorhexidine 2\% & 3 & $0.84 \times 10^{4} \pm 1.29 \times 10^{4}$ & $4.93 \times 10^{7}$ \\
Control (PBS) & 3 & $16.6 \times 10^{7} \pm 4.04 \times 10^{7}$ & $-2.36 \times 10^{4}$ \\
\hline
\end{tabular}

SD: Standard deviation, PBS: Phosphate-buffered saline

Table 2: Statistical summary of pair-wise comparisons between individual treatment groups

\begin{tabular}{llll}
\hline Treatment & Green tea 6\% & Chlorhexidine 2\% & Control \\
\hline Green tea 6\% & - & $0.05^{*}$ & $0.05^{*}$ \\
Chlorhexidine 2\% & $0.05^{*}$ & - & $0.05^{*}$ \\
Control & $0.05^{*}$ & $0.05^{*}$ & - \\
\hline
\end{tabular}

${ }^{*} \mathrm{p}<0.05$ significant by Mann-Whitney U-test

(PBS solution to release bacteria not firmly attached to the membrane (planktonic bacteria). Washed membranes were inserted into Eppendorf tubes containing either 1 -ml PBS (control), $1 \mathrm{ml}$ of $6 \%$ green tea extract, or $1 \mathrm{ml}$ of $2 \%$ chlorhexidine solution ( 3 tubes and membranes per treatment group) and incubated for $10 \mathrm{~min}$ at $37^{\circ} \mathrm{C}$ in an anaerobic incubator.

\section{Isolation of Enterococcus faecalis ATCC 29212 from biofilm} following treatment

All membranes exposed to the test solutions were washed three times with 1-ml PBS, each time in a new Eppendorf tube, to neutralize and stop antibacterial activity. The third Eppendorf tube with the membrane was then vortexed for 2 min to obtain the bacterial suspension, and the membrane removed aseptically.

\section{Photoconjugation of dead-cell DNA with propidium monoazide} After cell isolation and before DNA extraction and polymerase chain reaction (PCR) amplification, the bacterial suspension (100- $\mu \mathrm{L}$ samples in Eppendorf tubes) was treated with the photoreactive DNA dye PMA at a final concentration of $100 \mu \mathrm{M}$ to prevent subsequent PCR amplification of DNA from dead cells. Briefly, tubes were incubated for 10 min at $4 \mathrm{C}$ in a dark room, then placed horizontally on dry ice, and exposed to $600 \mathrm{Watt}$ halogen rays at a distance of $20 \mathrm{~cm}$ for $20 \mathrm{~min}$.

\section{DNA extraction}

A water bath incubator was prepared at $56^{\circ} \mathrm{C}$ and thermoblock units at $100^{\circ} \mathrm{C}$. The bacterial sample was resuspended by vortexing for $10 \mathrm{~s}$ and centrifuged at $10000 \mathrm{rpm}$ for $3 \mathrm{~min}$. After centrifugation, the supernatant was removed by micropipette and discarded, leaving only the raw cell pellet. The pellet was then mixed with $200-\mu$ InstaGene ${ }^{\mathrm{T}}$ Matrix over a hot plate with magnetic stirring, incubated in a water bath at $56^{\circ} \mathrm{C}$ for $30 \mathrm{~min}$, and mixed again by vortexing for $10 \mathrm{~s}$. The tube was then inserted into the thermoblock at $100^{\circ} \mathrm{C}$ for $8 \mathrm{~min}$. This procedure was repeated up to 3 times to solubilize DNA and precipitate cellular components that interfere with PCR.

The sample was then homogenized by vortexing for $10 \mathrm{~s}$ and centrifuged at 12,000 rpm for $3 \mathrm{~min}$. The supernatant was transferred into a new microcentrifuge tube and stored at $4^{\circ} \mathrm{C}$ for $24 \mathrm{~h}$. If deposit was still visible on the tube, the supernatant was transferred again into a new microcentrifuge tube and stored at $-20^{\circ} \mathrm{C}$ for additional DNA purification.

\section{Quantification of sample DNA concentration}

A working solution was prepared by adding Quant-iT ${ }^{\mathrm{m} M}$ DNA-BR Buffer $(199 \mu \mathrm{l} \times \mathrm{n}$ where $\mathrm{n}=$ number of samples, in this case 9) into $15 \mathrm{ml}$ centrifuge tubes pre-covered with aluminum foil. Then, $1 \mu \mathrm{l} \times 9$ Quant-iT ${ }^{\text {TM }}$ Reagent DNA-BR was added and mixed in using a vortex. This working solution $(199 \mu \mathrm{l})$ was mixed with $1-\mu \mathrm{l}$ sample DNA in a $0.5-\mathrm{ml}$ microcentrifuge tube covered with aluminum foil, and the new mixture was vortexed for $2 \mathrm{~s}$. Total DNA was then measured against a kit standard on a microplate reader at 502/523-nm excitation/emission.
Detection and Quantification of live Enterococcus faecalis ATCC DNA 29212

Primers EF Gro ES-F and EF Gro ES-R were diluted in TE buffer at 9:1, mixed by vortexing, and briefly centrifuged. A PCR mix was then prepared by multiplying each component volume by the number of samples to be examined using real-time PCR in $1.5-\mathrm{ml}$ microcentrifuge tubes coated with aluminum foil. The final mixture contains $10-\mu \mathrm{l}$ Power SYBR ${ }^{\circledast}$ Green PCR Master Mix l, 2- $\mu$ l universal primer 357F, 2- $\mu \mathrm{l}$ universal primer 907R, and 2- $\mu \mathrm{l}$ nuclease-free water. Then, $16 \mu \mathrm{l}$ was added to 4- $\mu$ l DNA sample in MicroAMP ${ }^{\mathrm{TM}}$ Fast Reaction Tubes and mixed using a micropipette.

MicroAmp ${ }^{\mathrm{TM}}$ Fast Reaction Tubes (8 tubes/strips) were covered with the MicroAmp ${ }^{T M}$ Optical 8-Cap Strip aseptically. A PCR well plate was then inserted into the Step One Real-Time PCR System (Applied Biosystems). The real-time PCR quantitative cycle was $95^{\circ} \mathrm{C}$ for $3 \mathrm{~min}$ (pre-activation), followed by 40 cycles of denaturation at $95^{\circ} \mathrm{C}$ for $15 \mathrm{~s}$, primer annealing at $55^{\circ} \mathrm{C}$ for $30 \mathrm{~s}$, and elongation at $72^{\circ} \mathrm{C}$ for $30 \mathrm{~s}$. After real-time PCR, the results could be read on the computer screen.

\section{Statistical analyses}

The numbers of surviving E. faecalis in samples from control, green tea, and chlorhexidine treatment groups were analyzed for normality and homogeneity of variance. If the data distribution was normal and the variance homogeneous, statistical analysis was performed using one-way ANOVA and post hoc least significant difference tests for pairwise comparisons. If the data distribution was not normal or the data variance was not homogeneous, treatment groups were compared by the non-parametric Kruskal-Wallis test with post hoc Mann-Whitney U-tests for pair-wise comparisons.

\section{RESULTS}

Table 1 presents the mean ( \pm standard deviation) number of surviving E. faecalis bacteria following control, green tea, or chlorhexidine treatment ( $\mathrm{n}=3$ samples/treatment group). The Kruskal-Wallis test indicated a significant difference among treatment groups $(\mathrm{p}=0.027)$, and post hoc pair-wise comparisons revealed significant differences between all groups ( $\mathrm{p} \leq 0.05$ by Mann-Whitney $\mathrm{U}$-test). Thus, both green tea extract and chlorhexidine reduced E. faecalis numbers compared to control treatment. However, the final count was significantly lower following chlorhexidine treatment compared to green tea extract treatment. Table 2 presents the results of the Mann-Whitney U-test for each pair-wise comparison

\section{DISCUSSION}

Green tea extract was examined as a possible treatment to eliminate oral E. faecalis biofilm because it has demonstrated antimicrobial efficacy as well as additional health benefits without cellular toxicity. Indeed, $6 \%$ green tea extract did significantly reduce $E$. faecalis numbers in artificial biofilms compared to control treatment but not as effectively as $2 \%$ chlorhexidine $[2,4]$. Thus, green tea extract may help reduce $E$. faecalis biofilms although alone it is not as clinically effective as chlorhexidine. It is possible, however, that bioactive components in green tea extract may be high-potency natural agents for $E$. faecalis biofilm elimination.

The antibacterial activity of green tea is most strongly associated with a polyphenol catechin fraction containing about $30 \%$ of the natural epigallocatechin-3-gallate (EGCG), a compound that accounts for 50\% of the total catechin content and can cause irreversible membrane 
damage to Gram-positive bacteria. In addition, EGCG can also inhibit bacterial DNA gyrase enzymes by binding to ATP B subunits, preventing DNA supercoiling, and causing bacterial cell death.

The tea leaves used for extract preparation in this study were of the imperial type obtained from a research center for tea and quinine (PPTK Bandung). Imperial is a pekoe tea produced from young tea shoots, and it is known that younger tea shoots contain higher levels of polyphenols than mature leaves. According to PPTK Bandung, this type of pekoe tea has the highest polyphenol concentration (36.91\%) and a catechin content of about $26.5 \%$. In this study, the green tea solution was used at $6 \%$, a concentration selected based on a study by Martina et al. reporting that concentrations of 3\%-6\% eliminate E. faecalis growth [3]. According to Martina et al., 3\% green tea extract had antibacterial activity comparable to $2 \%$ chlorhexidine [3]. In our preliminary experiments, however, E. faecalis growth was still observed in $3 \%$ green tea extract while growth of new $E$ faecalis bacteria was not detectable at $6 \%$, comparable to results using $2 \%$ chlorhexidine. This difference in antimicrobial potency between our study and Martina et al. likely stems from differences in the natural polyphenol catechin content, which may be influenced the geographic location of cultivation, growth conditions, processing, and extract preparation methods [3]. In this study, E. faecalis biofilm was exposed to each test material for 10 min, a duration chosen according to Kim et al., who found that maximum attachment of antibacterial particles to the bacterial cell wall required more than $5 \mathrm{~min}$ and that $10 \mathrm{~min}$ was sufficient for antibacterial substances to adhere and cause substantial damage to the E. faecalis membrane [5].

Traditional microbiology methods used to quantify bacteria for toxicity analysis are time-consuming and non-specific. In contrast, PCR using specific primers allows for rapid and sensitive detection of individual species [6]. However, PCR techniques also have limitations, especially for assessing the effectiveness of an antimicrobial agent. Conventional PCR can only detect the presence or absence of bacteria but not the quantity, while real-time PCR of untreated bacteria cannot distinguish between living and dead cells because bacterial DNA is stable in the environment for long periods after cell death $[7,8]$. To overcome this problem, cells were first stained with propidium monoazide (PMA), which forms covalent bonds with DNA bases upon photoactivation, thereby inhibiting PCR amplification of DNA from dead cells but not living cells [9]. Further, PMA cannot penetrate the intact cell membrane and so will only react with the DNA from irreversibly damaged cells. By blocking PCR amplification of DNA from dead cells, it was possible to accurately determine the antimicrobial efficacies of green tea extract and chlorhexidine against $E$. faecalis in biofilms [10].

The antibacterial efficacy of green tea extract against E. faecalis cultured in artificial biofilm is in accord with Garg et al., who found that green tea polyphenols have substantial antibacterial power against $E$. faecalis biofilm [9]. However, the green tea polyphenols tested in that study were extracted with dimethyl sulfoxide (DMSO) rather than water and so likely include unique compounds.

While green tea did reduce the number of surviving $E$. faecalis, total survival was still higher than after chlorhexidine $2 \%$ treatment. These results differ from those of Martina et al., who reported that $3 \%$ green tea extract had antibacterial activity comparable to chlorhexidine $2 \%$ [3]. This difference may be explained by the different bacterial forms as planktonic bacteria are more easily eliminated than bacteria in biofilm. In biofilm, genetic and metabolic changes as well as the formation of a thick extracellular polymeric substance block access of some antimicrobial agents, thereby enhancing resistance 500-1000fold compared to planktonic cells [11]. As mentioned, differences in antimicrobial efficacy among studies are also related to the natural EGCG content of the extract. Thus, it is necessary to examine the antimicrobial efficacies of purified catechin compounds directly, particularly EGCG, as it is the most active and abundant component of catechin. Moreover, EGCG extract of green tea is commercially available in powder at $50 \%-98 \%$ and is already used as a natural ingredient for medicines, dietary supplements, beverages, and cosmetics due to its low toxicity.

\section{CONCLUSION}

Green tea extract solution had antibacterial efficacy against $E$. faecalis in biofilm. However, the efficacy of $6 \%$ green tea extract is lower than chlorhexidine $2 \%$ solution. Nonetheless, these results suggest that specific bioactive components of green tea extract, such as EGCG, are potentially effective non-toxic agents for the reduction of oral $E$. faecalis biofilm.

\section{CONFLICTS OF INTERESTS}

There are no conflicts of interest to declare.

\section{REFERENCES}

1. Halkai R, Hegde MN, Halkai K. Enterococcus faecalis can survive extreme challenges-overview. Nitte Univ J Health Sci 2012;2:49-52.

2. Chacko SM, Thambi PT, Kuttan R, Nishigaki I. Beneficial effects of green tea: A literature review. Chin Med 2010:5:13.

3. Martina LP, Vedamanickam A, Ebenezar R, Ghani MF, Narayanan A, Sundaram $\mathrm{M}$, et al. An in vitro comparative antibacterial study of different concentrations of green tea extracts and $2 \%$ chlorhexidine on Enterococcus faecalis. Saudi Endod J 2013;3:120-4.

4. Reygaert WC. The antimicrobial possibilities of green tea. Front Microbiol 2014;5:434.

5. Kim H-S, Chang SW, Baek S-H, Han SH, Lee Y, Zhu Q, et al. Antimicrobial effect of alexidine and chlorhexidine against Enterococcus faecalis infection. Int J Oral Sci 2013;5:26-31.

6. Cogulu D, Uzel A, Oncag O, Aksoy SC, Eronat C. Detection of Enterococcus faecalis in necrotic teeth root canals by culture and polymerase chain reaction methods. Eur J Dent 2007;1:216-21.

7. Sánchez MC, Marín MJ, Figuero E, Llama-Palacios A, Herrera D, Sanz M, et al. Analysis of viable vs. Dead aggregatibacter actinomycetemcomitans and Porphyromonas gingivalis using selective quantitative real-time PCR with propidium monoazide. J Periodontal Res 2013;48:213-20.

8. Sanchez MC, Marin MJ, Figuero E, Palacios AL, Leon R, Blanc V, Herrera D, Sanz M. Quantitative real-time PCR combined with propidium monoazide for the selective quantification of viable periodontal pathogens in an in vitro subgingival biofilm model. J Period Res 2013:1-8.

9. Garg P, Tyagi SP, Sinha DJ, Singh UP, Malik V, Maccune ER. Comparison of antimicrobial efficacy of propolis, Morinda citrifolia, Azadirachta indica, triphala, green tea polyphenols and $5.25 \%$ sodium hypochlorite against Enterococcus faecalis biofilm. Saudi Endod J 2014;4:122-6.

10. Life Technologies. Real-time PCR Handbook. Available from: http:// www.find.lifetechnologies.com/Global/FileLib/qPCR/RealTimePCR Han. [Last accessed on 2014 Nov 15].

11. Prabhakar J, Senthilkumar M, Priya MS, Mahalakshmi K, Sehgal PK, Sukumaran VG, et al. Evaluation of antimicrobial efficacy of herbal alternatives (Triphala and green tea polyphenols), MTAD, and 5\% sodium hypochlorite against Enterococcus faecalis biofilm formed on tooth substrate: An in vitro study. J Endod 2010;36:83-6. 